\title{
Selective impairment of insulin signalling in the hypothalamus of obese Zucker rats
}

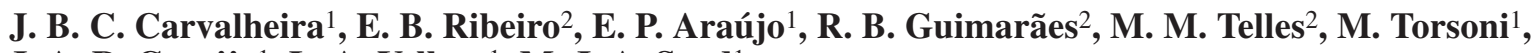 \\ J. A. R. Gontijo ${ }^{1}$, L. A. Velloso ${ }^{1}$, M. J. A. Saad ${ }^{1}$ \\ ${ }^{1}$ Departamento de Clínica Médica, FCM, Universidade Estadual de Campinas (UNICAMP), Brasil \\ ${ }^{2}$ Departamento de Fisiologia, Universidade Federal de São Paulo (UNIFESP), São Paulo, SP, Brasil
}

\section{Abstract}

Aim/hypothesis. By acting in the brain, insulin suppresses food intake. However, little is known with regard to insulin signalling in the hypothalamus in insulin-resistant states.

Methods. Western blotting, immunohistochemistry and polymerase chain reaction assays were combined to compare in vivo hypothalamic insulin signalling through the PI3-kinase and MAP kinase pathways between lean and obese Zucker rats.

Results. Intracerebroventricular insulin infusion reduced food intake in lean rats to a greater extent than that observed in obese rats, and pre-treatment with PI3-kinase inhibitors prevented insulin-induced anorexia. The relative abundance of IRS-2 was considerably higher than that of IRS-1 in hypothalamus of both lean and obese rats. Insulin-stimulated phosphorylation of IR, IRS-1/2, the associations of PI 3-kinase to IRS-1/2 and phosphorylation of Akt in hypothalamus were decreased in obese rats compared to lean rats. These effects seem to be mediated by increased phosphoserine content of IR, IRS-1/2 and decreased protein levels of IRS-1/2 in obese rats. In contrast, insulin stimulated the phosphorylation of MAP kinase equally in lean and obese rats.

Conclusion/interpretation. This study provides direct measurements of insulin signalling in hypothalamus, and documents selective resistance to insulin signalling in hypothalamus of Zucker rats. These findings provide support for the hypothesis that insulin could have anti-obesity actions mediated by the PI3-kinase pathway, and that impaired insulin signalling in hypothalamus could play a role in the development of obesity in this animal model of insulin-resistance. [Diabetologia (2003) 46:1629-1640]

Keywords Obesity, insulin resistance, hypothalamus, anorexia, signal transduction, phosphatidylinositol 3-kinase/antagonists \& inhibitors/*metabolism, mitogen-activated protein kinase.
Received: 10 April 2003 / Revised: 4 August 2003

Published online: 5 November 2003

(C) Springer-Verlag 2003

Corresponding author: M. J. A. Saad, Departamento de Clínica Médica, FCM, Universidade Estadual de Campinas (UNICAMP), 13081-970 Campinas, SP, Brasil

E-mail: msaad@fcm.unicamp.br

Abbreviations: ERK, extracellular signal-regulated kinase; Grb2, growth factor receptor binding protein 2; IR, insulin receptor; IRS, insulin receptor substrate; MAPK, mitogen-activated protein kinase; PI 3-kinase, phosphatidylinositol 3-kinase; PKC, Protein kinase C; Shc, Src-homology and collagen homology; SHP2, Src-homology phosphatase 2; TNF- $\alpha$, Tumor-necrosis factor- $\alpha$.
Insulin receptors (IR) are expressed in most tissues of the body, including the classic insulin-sensitive tissues (liver, muscle and fat), as well as "insulin-insensitive" tissues, such as red blood cells and neurons of the CNS. In the CNS, the IR has distinct patterns of expression in the olfactory bulb, the hypothalamus and the pituitary $[1,2,3]$, although its function in these regions is not completely understood. Previous studies have documented a role for insulin signalling in the regulation of food intake $[4,5,6,7,8]$.

In the past decade, many of the proteins involved in insulin action have been defined at the molecular level in non-hypothalamic cells. The insulin receptor is a 
protein tyrosine kinase which, when activated by insulin binding, undergoes rapid autophosphorylation and phosphorylates intracellular protein substrates, including insulin receptor substrates (IRSs-IRS-1 and IRS2 are the most important) $[9,10,11]$ and Shc [12]. Following tyrosine phosphorylation, the IRSs act as docking proteins for several Src homology 2 domaincontaining proteins, including phosphatidylinositol 3kinase (PI3-kinase), Grb2, SHP2, Nck and Fyn [13, $14,15,16,17]$. Downstream to PI 3-kinase there is activation of a serine/threonine kinase, Akt [18]. In contrast, downstream to Grb2 there is activation of the mitogen-activated protein kinase (MAPK-ERK), which is important in the regulation of gene-expression and cell growth $[19,20,21]$.

Besides its epidemiological association with obesity, insulin resistance and hyperinsulinaemia could also primarily contribute to the development of obesity [22]. Mechanisms to explain the weight gain caused by insulin resistance and hyperinsulinaemia have been attributed to defective insulin signalling in the hypothalamus $[4,6,22,23,24,25,26]$. However, the intracellular mechanisms involved are largely unknown. In light of recent studies showing that the hypothalamic PI3-kinase pathway is central for the control of food intake [27, 28], we decided to characterize the direct actions of insulin on the PI3-kinase and MAPK pathways in the hypothalamus of both lean and obese Zucker rats.

\section{Materials and methods}

Animals. We studied 4- to 5-month-old male Zucker rats (Charles River Breeding Laboratories, Wilmington, Mass., USA). All experiments involving animals were in accordance with the guidelines of the Brazilian College for Animal Experimentation (COBEA) and were approved by the ethics committee at the University of Campinas. Room temperature was maintained between $21-23^{\circ} \mathrm{C}$, rats were housed in individual cages, subjected to a standard light-dark cycle (06:00-18:00/ 18:00-06:00) and provided with standard rodent chow and water ad libitum. All experiments for determination of food consumption and insulin signalling were started between 17:00 and 18:00.

Reagents. Insulin (Eli Lilly, Indianapolis, Ind.,USA) was stored at $4^{\circ} \mathrm{C}$. Stock solutions were diluted in saline immediately before each experiment. The PI3-kinase inhibitors, Wortmannin and LY294002 (Calbiochem, San Diego, Calif., USA), were dissolved in dimethyl sulfoxide and further diluted in saline (dimethyl sulfoxide $0.1 \%$ ).

Determination of plasma glucose and serum insulin concentration. Plasma glucose was measured by glucose oxidase method in samples collected from the tail. Serum insulin was detected by RIA, utilizing a guinea pig anti-rat insulin antibody and rat insulin as standard [29].

Surgical procedures. After an overnight fast, the rats were anaesthetised with ketamine hydrochloride (100 mg/kg, ip) and positioned on a Stoelting stereotaxic apparatus. The scalp was removed in the midline to expose the saggital suture, and the periosteum was then opened and reflected away from the surgical field. The lateral, anteroposterior and dorsoventral coordinates of the lateral ventricle were obtained from a standard atlas [30]. The bregma was used as the reference point and a hole was drilled in the parietal bone at the junction of the lateral and anteroposterior coordinates. The cannula was positioned over the hole and lowered carefully until the necessary dorsoventral coordinate was reached. The rats were then allowed to recover from anaesthesia and the surgical procedure for 7 days. Cannula placement was confirmed by a positive drinking response after administration of angiotensin II $(40 \mathrm{ng} / 2 \mu \mathrm{l})$, and animals that did not drink $5 \mathrm{ml}$ of water within $15 \mathrm{~min}$ after treatment were not included in the experiment.

Treatments and measurement of food intake. Rats deprived of food for $6 \mathrm{~h}$ with free access to water were i.c.v. injected $(2 \mu \mathrm{l}$ bolus injection) with either vehicle, insulin (2 and $200 \mathrm{mU})$,

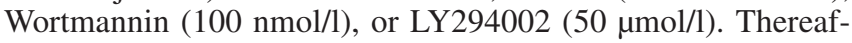
ter standard chow was given and food intake was determined by measuring the difference between the weight of chow given and the weight of chow at the end of a 12 -h period. Similar studies were carried out in rats that were initially i.c.v. injected with the PI3-kinase inhibitors, Wortmannin (100 nmol/l) or LY294002 $(50 \mu \mathrm{mol} / \mathrm{l})$, or vehicle, and after $30 \mathrm{~min}$ with insulin $(200 \mathrm{mU})$. In preliminary experiments we determined plasma glucose and serum insulin concentrations in animals that received i.c.v. insulin infusion. Insulinaemia and plasma glucose were not altered by lateral ventricle insulin or saline microinjection (data not shown).

Polymerase chain reaction (PCR) amplification and digestion of PCR products. PCR amplification was carried out on isolated DNA from blood of lean and obese rats using a GFX ${ }^{\mathrm{TM}}$ genomic blood DNA purification kit (Amersham Pharmacia Biotech, Piscataway, N.J., USA) according to the manufacturer's instructions. Primers, (5'-GTT TGC GTA TGG AAG TCA CAG-3') and (5'-ACC AGC AGA GAT GTA TCC GAG-3') were used to amplify products from $100 \mathrm{ng}$ genomic DNA. PCR reactions were carried out in $50 \mu \mathrm{l}$ containing $100 \mathrm{ng}$ DNA, $100 \mathrm{ng}$ of each primer, $500 \mu \mathrm{mol} / 1 \mathrm{dNTPs}, 1 \times$ Buffer 3 from the expanded long template PCR kit (Boehringer Mannheim Biochemicals, Indianapolis, Ind., USA), $0.25 \mu \mathrm{l}$ each of AmpliTaq Polymerase (Perkin Elmer, Boston, Mass., USA) and Taq extender (Stratagene, La Jolla, Calif., USA). The amplification protocol was 32 cycles at $92^{\circ} \mathrm{C}$ for $30 \mathrm{~s}$, at $54^{\circ} \mathrm{C}$ for $1 \mathrm{~min}$ and at $68^{\circ} \mathrm{C}$ for $5 \mathrm{~min}$. All PCR products were digested with $\mathrm{MspI}$ overnight at $37^{\circ} \mathrm{C}$ and analyzed on a $1 \%$ agarose gel.

Western blot analysis. The rats were anaesthetised with sodium amobarbital (15 mg/kg body weight, ip), and used as soon as anaesthesia was assured by the loss of pedal and corneal reflexes. Rats were i.c.v. injected ( $2 \mu \mathrm{l}$ bolus injection) with either vehicle, insulin (2 and $200 \mathrm{mU})$, or Wortmannin (100 nmol/l), LY294002 (50 $\mu \mathrm{mol} / \mathrm{l})$. After the appropriate time interval (15 min), the rats were killed, the cranium was opened and the basal diencephalon, including the pre-optic area and the hypothalamus, was quickly removed, minced coarsely and homogenized immediately in the solubilization buffer containing $100 \mathrm{mmol} / \mathrm{l}$ Tris ( $\mathrm{pH} 7.6$ ), 1\% Triton X-100, $150 \mathrm{mmol} / \mathrm{l} \mathrm{NaCl}, 0.1 \mathrm{mg}$ aprotinin, $35 \mathrm{mg} \mathrm{PMSF} / \mathrm{ml}$, $10 \mathrm{mmol} / \mathrm{l} \mathrm{Na} \mathrm{VO}_{4}, 100 \mathrm{mmol} / \mathrm{l} \mathrm{NaF}, 10 \mathrm{mmol} / \mathrm{l} \mathrm{Na} \mathrm{P}_{2} \mathrm{O}_{7}$, and $4 \mathrm{mmol} / \mathrm{l}$ EDTA, using a Polytron PTA 20S generator operated at maximum speed for $30 \mathrm{~s}$ and clarified by centrifugation. Invariably two hypothalami were pooled and $200 \mu \mathrm{g}$ of protein were used as whole tissue extract for Akt and Erk analysis or 
$1 \mathrm{mg}$ protein for immunoprecipitation followed by western blot for IR and IRS-1/2 with the indicated antibodies and [125I]Protein A. Quantitative analysis of the blots was done using Scion Image software (Scion Corporation, Frederick, Md., USA). [ ${ }^{125 I}$ ]Protein A bound to the anti-phosphotyrosine and antipeptide antibodies was detected by autoradiography using preflashed Kodak XAR film (Eastman Kodak, Rochester, N.Y., USA) with Cronex Lightning Plus intensifying screens at $-80^{\circ} \mathrm{C}$ for $12-48 \mathrm{~h}$. Similar studies were done in rats i.c.v. injected with the PI3-kinase inhibitors, Wortmannin (100 nmol/l) or LY294002 $(50 \mu \mathrm{mol} / \mathrm{l})$, and $30 \mathrm{~min}$ after with insulin $(200 \mathrm{mU})$. The antibodies against IR (sc-711), IRS-1 (sc-559), IRS-2 (sc-8299), ERK (sc-93), p-ERK (sc-7383), Shc (sc-288), Akt1 (sc-1618) and anti-phosphotyrosine (sc-508) were obtained from Santa Cruz Biotechnology (Santa Cruz, Calif., USA). Antibodies against the p85 subunit of PI3-kinase (06-195) were from Upstate Biotechnology (Lake Placid, N.Y., USA). Antibodies against Akt phosphoserine specific (9271L) were purchased from Cell Signaling Technology (Beverly, Mass., USA). Phospho-Serine antibodies (AB1603) were obtained from Chemicon International (Temecula, Calif., USA).

Since different antibody affinities towards IRS-1 and IRS-2 could raise concerns about hypothalamic substrate concentration and its tyrosine phosphorylation we evaluated the affinity of the antibodies used in this study (IRS-1 sc-559; IRS-2 sc-8299). For this purpose a protein A Sepharose column was assembled and the affinity of each antibody to liver IRS-1 and IRS-2 was tested under a salt gradient $[31,32]$. The affinity of sc-559 towards IRS1 was about three-fold higher than the affinity of sc-8299 towards IRS-2. Antibody cross-reactivity was almost undetectable as evaluated by eluate separation on SDSPAGE and western blot analysis.

Immunohistochemistry. Rat hypothalami were fixed in $4 \%$ paraformaldehyde/0.2 mol/l phosphate-buffered saline ( $\mathrm{pH} 7.4$ ) for $24 \mathrm{~h}$, embedded in paraffin, and $5 \mu \mathrm{m}$ sections were obtained. The glass-mounted sections were cleared from paraffin with xylene and re-hydrated by sequential washings with graded ethanol solutions (70-100\%). After permeabilization with $0.1 \%$ Triton $\mathrm{X}-100$ in phosphate-buffered saline, $\mathrm{pH} 7.4$, for $10 \mathrm{~min}$ at room temperature, the sections were incubated in $1 \%$ $\mathrm{H}_{2} \mathrm{O}_{2}$ in phosphate-buffered saline for $30 \mathrm{~min}$ to quench the endogenous peroxidase activity. The sections were pre-treated in a microwave oven in sodium citrate buffer $(\mathrm{pH} 7.4)$ for $10 \mathrm{~min}$. After being washed in phosphate-buffered saline, the sections were blocked by $3 \%$ non-fat dry milk in phosphatebuffered saline for $1 \mathrm{~h}$ at $37^{\circ} \mathrm{C}$, followed by overnight incubation with the primary antibody (rabbit anti-IR, rabbit anti-IRS1 or goat anti-IRS2) in $1 \%$ BSA in phosphate-buffered saline at $4^{\circ} \mathrm{C}$ in a moisture chamber. After incubation with the primary antibody, sections were washed and incubated with a specific biotinylated anti-rabbit secondary antibody (1:150 dilution) for $2 \mathrm{~h}$ at room temperature, followed by incubation with Streptoavidin reagent (containing avidin-conjugated peroxidase) and colour reaction using the DAB substrate kit (Vector Laboratories, Burlingame, Calif., USA) according to recommendations of the manufacturer. After the colour reaction, sections were counterstained with Harris haematoxylin, dehydrated through an ethanol series into xylene and mounted using Entellan mounting media (Microscopy, Darmstadt, Germany). Secondary antibody specificity was tested in a series of positive and negative control measurements. In the absence of primary antibodies, application of secondary antibodies (negative controls) failed to produce any staining. The images were obtained using an optical microscope (Leica, Wetzlar, Germany) and a Focus Imagecorder Plus System. For double immunofluorescence staining FITC and rhodamine conjugated secondary antibodies were used and analysis and photo-documentation were done using a Zeiss LSM 510 Laser Scanning Confocal Microscope [33].

Statistical analysis. Where appropriate, the results were expressed as the means \pm SEM accompanied by the indicated number of rats used in experiments. Comparisons among groups were made using parametric two-way ANOVA, where F ratios were significant. Further comparisons were made using Newman-Keuls test. A $p$ value of less than 0.05 was considered statitically significant.

\section{Results}

Intracerebroventricular insulin reduces food intake in lean rats to a greater extend than in obese Zucker rats. The obese rats were heavier and had higher plasma glucose and fasting serum insulin concentrations than their age-matched lean controls (Table 1). The effect of insulin ( 2 and $200 \mathrm{mU}$ ) or its saline vehicle on the control of food intake was studied in 6-h fasted rats by measuring the total food intake for 12-h after a single i.c.v. injection of insulin or its saline vehicle just before the onset of the dark cycle. Insulin, in a concentration-dependent manner, induced reductions in the 12-h food intake of both lean (+/?) and obese $(f a / f a)$ rats. In the lean rats, insulin $(2 \mathrm{mU}$ and $200 \mathrm{mU}$ ) food intake by about $50 \%$ and about $90 \%$, respectively, while in the obese rats these doses induced reductions of about $30 \%$ and about $45 \%$ respectively, indicating that insulin was much less effective in obese rats (Fig. 1).

Detection of the A880 to C mutation in genomic DNA. In order to genotype lean and obese animals PCR primers that amplify a 157-bp cDNA fragment, containing the $\mathrm{A}^{880}$ to $\mathrm{C}$ mutation, were used to amplify

Table 1. Characteristics of obese Zucker $(f a / f a)$ rats and their age-matched lean Zucker ( Fal?) controls

\begin{tabular}{llllll}
\hline Groups & $\begin{array}{l}\text { Number of rats } \\
(n)\end{array}$ & $\begin{array}{l}\text { Body weight } \\
(\mathrm{g})\end{array}$ & $\begin{array}{l}\text { Plasma glucose } \\
(\mathrm{mmol} / \mathrm{l})\end{array}$ & $\begin{array}{l}\text { Fasting insulin } \\
(\mathrm{pmol} / \mathrm{l})\end{array}$ & $\begin{array}{l}\text { Post-prandial insulin } \\
(\mathrm{pmol} / \mathrm{l})\end{array}$ \\
\hline Lean $(+/+)$ & 6 & $254 \pm 27$ & $4.6 \pm 0.28$ & $104.2 \pm 27.8$ & $771.8 \pm 56.1$ \\
Lean $(+/ f a)$ & 6 & $265 \pm 21$ & $4.88 \pm 0.33$ & $131.9 \pm 55.6$ & $817.8 \pm 74.3$ \\
Obese $(\mathrm{fa} / \mathrm{fa})$ & 10 & $394 \pm 20^{*}$ & $6.16 \pm 0.22^{*}$ & $1757.1 \pm 111.1^{*}$ & $7028.6 \pm 390.9^{*}$ \\
\hline
\end{tabular}

\footnotetext{
${ }^{*} p<0.001$ vs. lean group
} 


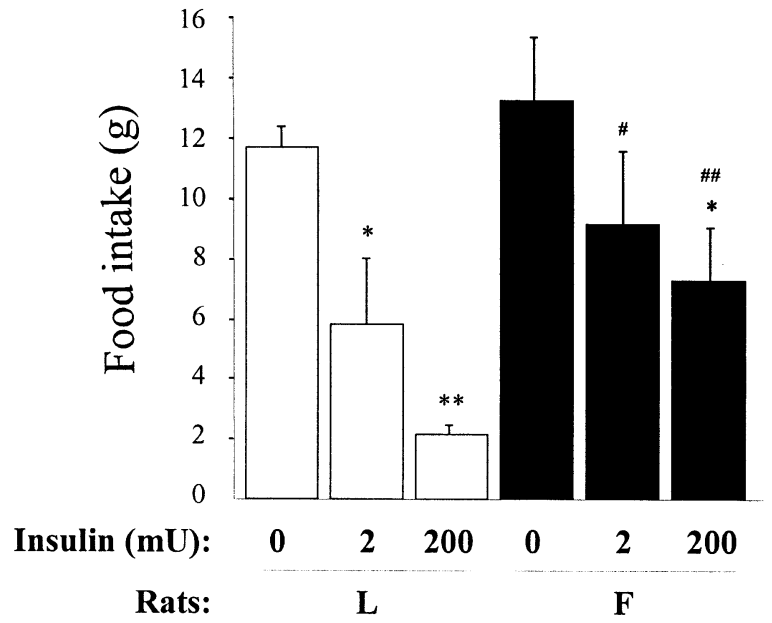

Fig. 1. Dose-related inhibition of the 12-h cumulative food intake induced by insulin in lean (L) and obese (F) Zucker rats fasted for 6 h. Vehicle or insulin was injected i.c.v. at the onset of the dark cycle and rats were immediately exposed to food for $12 \mathrm{~h}$. Data are expressed as means \pm SEM of 8-14 animals per group. ${ }^{\#} p<0.05$, ${ }^{\# \#} p<0.001$, vs the respective lean insulintreated group. ${ }^{*} p<0.05,{ }^{*} p<0.001$, vs. vehicle injected rats

a

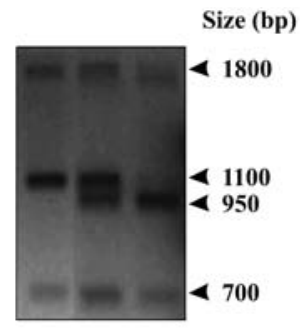

Genotype: $+/++/ f a$ falfa genomic DNA. A $1.8-\mathrm{kb}$ product was generated. MspI digestion of the $1.8-\mathrm{kb}$ fragment from homozygous lean animals showed a single restriction site (Fig. 2a, lane 1). In contrast, MspI digestion of genomic products from $\mathrm{fa} / \mathrm{fa}$ rats resulted in an additional cleavage of the largest fragment (lane 3). Some products from lean rats generated an $M s p I$ digestion pattern indicating that these lean animals were heterozygous for the mutation (lane 2).

In vivo effect of insulin on tyrosine phosphorylation of $I R$ in the hypothalamus. The protein expression of IR in the hypothalamus from lean $+/+$, lean $+/ f a$ and obese rats was quantitated by immunoprecipitation and immunoblotting with $\alpha$ IR antibodies. The IR protein levels were not different between lean $+/+$, lean $+/$ fa and obese rats (Fig. 2b).

The effect of in vivo i.c.v. insulin infusion on IR tyrosine phosphorylation was examined in the hypothalamus of Zucker lean (+/?) and obese ( $f a / f a)$ rats. Hypothalami from insulin or vehicle-treated rats were submitted to immunoprecipitation with anti-IR anti-

b

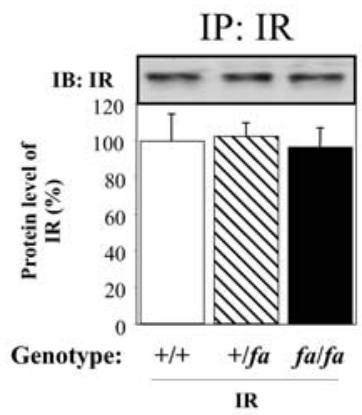

d

IP: IR

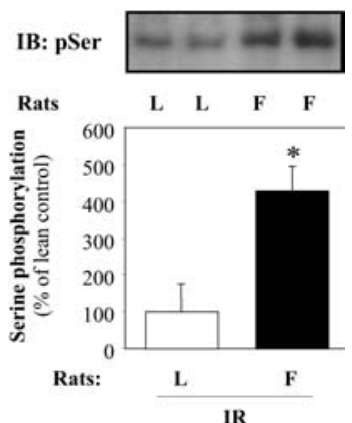

Fig. 2a-d. Detection of $A^{880}$ to $C$ mutation in genomic DNA, IR protein expression and tyrosine or serine phosphorylation in the hypothalamus of lean (L) and obese (F) Zucker rats in vivo. (a) Blood DNA amplification and MspI digestion of PCR products from lean and $f a / f a$ rats. Lane 1: Wild-type lean rat $(+/+)$, Lane 2: Heterozygous lean rat $(+/ f a)$, Lane 3: Obese falfa rat. (b) IR protein levels. Isolated hypothalami were homogenized, and equal amounts of protein were subjected to immunoprecipitation (IP) with $\alpha$ IR, separated by SDS-PAGE, and immunoblotted (IB, immunoblotting) with the same antibody. (c) Insulin-induced IR tyrosine phosphorylation. Hypo- thalamic extracts from lean and obese rats treated with insulin or vehicle for $15 \mathrm{~min}$. Tissue extracts were immunoprecipitated with anti-IR antibody and immunoblotted with anti-phosphotyrosine antibody (pY). (d) IR serine phosphorylation. Isolated hypothalami were homogenized, and equal amounts of protein were subjected to immunoprecipitation with $\alpha$ IR, separated by SDS-PAGE, and immunoblotted (with anti-phosphoserine antibody (pSer). Data (means \pm SEM; $n=8-10$ ) are expressed as relative to control, assigning a value of $100 \%$ to the lean insulin mean. ${ }^{*} p<0.05$ vs the respective lean insulin-treated group 
a
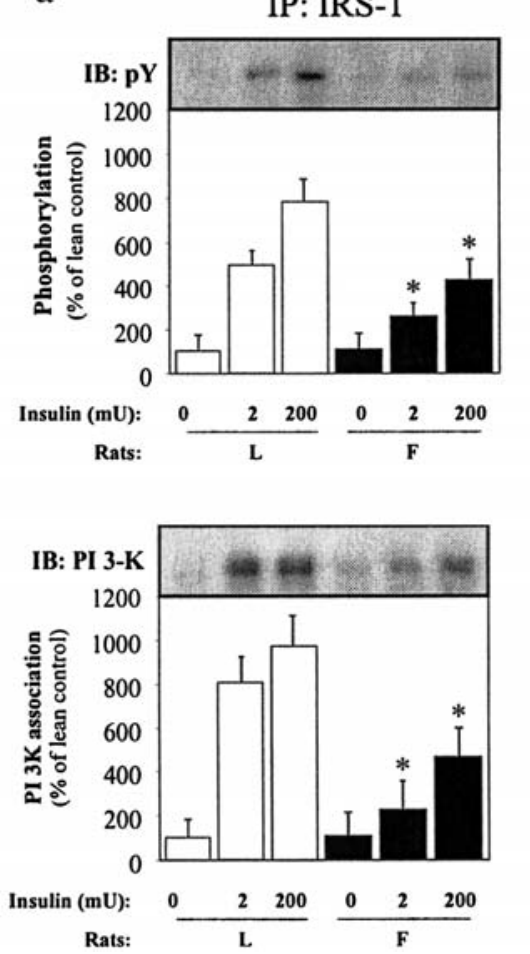

b
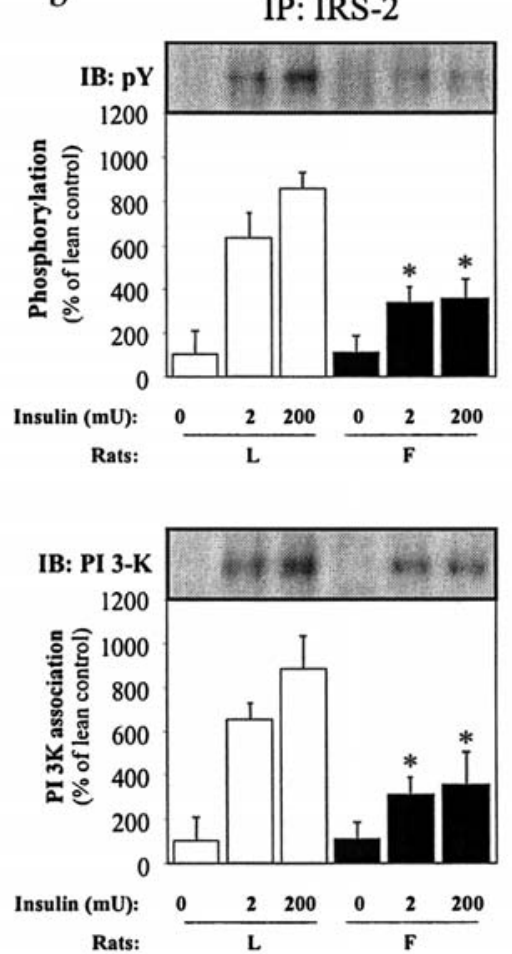

$\mathrm{c}$

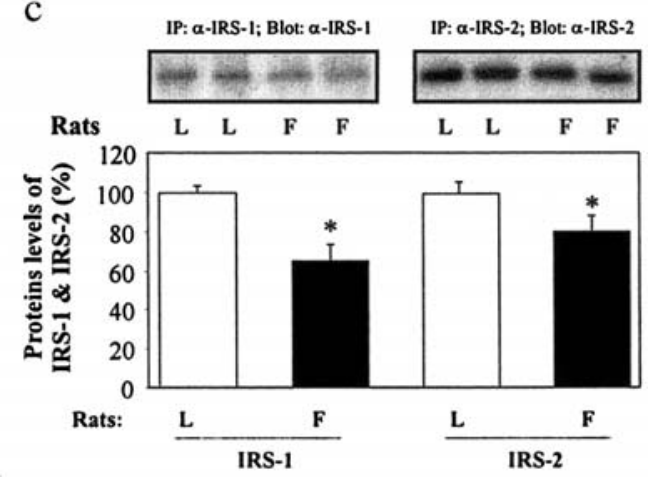

d

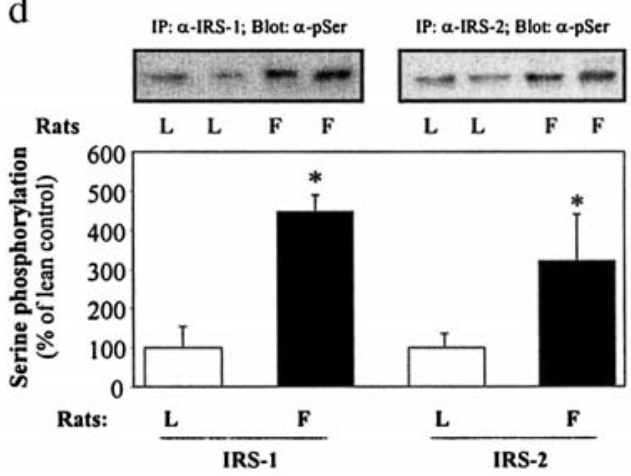

Fig. 3a-d. IRS-1 and IRS-2 protein expression, tyrosine and serine phosphorylation, and their association with the p85 subunit of PI 3-kinase in the hypothalamus of lean (L) and obese (F) Zucker rats in vivo. (a, b-upper panel) Insulin-stimulated tyrosine phosphorylation of IRS-1 and IRS-2. Hypothalami from rats treated with insulin or vehicle for 15 min were lysed, and tissue extracts were immunoprecipitated with anti-IRS-1 or anti-IRS-2 antibodies and blotted with anti-phosphotyrosine antibody (pY). (a, b-bottom panel) The same membranes used for IRS-1 and IRS-2 tyrosine phosphorylation were stripped and re-blotted with anti-PI3-kinase antibodies. Isolated hypothalami were homogenized, and equal amounts of protein were subjected to immunoprecipitation (IP) with $\alpha$ IRS-1 or $\alpha$ IRS-2, separated by SDS-PAGE, and immunoblotted (IB, immunoblotting) with the same antibody (c) or with anti-phosphoserine antibody (pSer) (d). The bar graph shows the quantitative serine phosphorylation of IRS-1 and IRS-2. Data (means $\pm \mathrm{SEM} ; n=8$ ) are expressed as relative to control, assigning a value of $100 \%$ to the lean insulin mean. ${ }^{*} p<0.05$, lean vs obese

body and then blotted with anti-phosphotyrosine antibody. Insulin, in a concentration-dependent manner, induced increases in IR tyrosine phosphorylation levels in hypothalamus from both lean and obese rats. In the lean animals, insulin ( $2 \mathrm{mU}$ and $200 \mathrm{mU}$ ) increased IR tyrosine phosphorylation by 4.9- and 9.1fold, respectively, compared with 2.8- and 3.9-fold increases in the hypothalami from obese rats, representing reductions in IR tyrosine phosphorylation of 53\% and $65 \%$ respectively (Fig. 2c). To determine whether the decreases in IR tyrosine phosphorylation in the obese rats were associated with an increase in IR serine phosphorylation, we carried out immunoprecipita- tion with anti-IR antibody and then blotted with antiphosphoserine antibody. The basal levels of IR serine phosphorylation were 4.5-fold higher in obese than in lean rats (Fig. 2d).

The $f a /+$ rats had similar weight as the $+/+$ animals, with mean body weight of $254.5 \pm 27.5$ and $265.0 \pm$ 21.2 , respectively. To assess if the Zucker mutation in the leptin receptor interferes with the control of food intake we measured the food intake of 6-h fasted lean $\mathrm{fa} /+$ and $+/+$ rats for $12 \mathrm{~h}$ after a single injection of insulin. The i.c.v. injection of insulin induced similar reductions in food intake of both lean $\mathrm{fa} /+$ and lean $+/+$ rat (data not shown). Insulin-stimulated tyrosine phosphorylation of IR equally in hypothalamus of both lean $+/+$ and lean $+/$ fa rats (Fig. 2c).

Effect of insulin on tyrosine phosphorylation of IRS1/2 and their association with the p85 subunit of PI 3kinase in the hypothalamus. Insulin, in a concentration-dependent manner, induced increases in IRS-1 and IRS-2 tyrosine phosphorylation levels in hypothalamus from both lean and obese rats. In the lean animals, insulin ( $2 \mathrm{mU}$ and $200 \mathrm{mU}$ ) increased IRS-1 tyrosine phosphorylation by 5.0- and 7.9-fold, respectively, compared with 2.5- and 4.2-fold increases in the hypothalami from obese rats, representing reductions of $62 \%$ and $54 \%$ in IRS-1 tyrosine phosphorylation, respectively (Fig. 3a). Insulin (2 mU and $200 \mathrm{mU}$ ) stimulated increases of 6.3-fold and 8.5-fold in IRS-2 tyrosine phosphorylation, respectively, in the hypothalamus of lean rats (Fig. 3b, upper panel), compared with increases of 3.3- and 3.5-fold, respectively, in the hypothalamus of obese rats, representing 
decreases of $43 \%$ and $66 \%$ in the obese rats $(p<0.05)$. The same membranes used to detect tyrosine phosphorylation of IRS-1 and IRS-2 were reblotted with antibodies against the p85 subunit of PI3-kinase. The PI3-kinase association to IRS-1 and IRS-2 paralleled the changes in phosphorylation of these proteins (Fig. 3a,b-bottom panels). The protein expression of IRS-1 and IRS-2 in the hypothalamus from control and obese rats were quantitated by immunoprecipitation and immunoblotting with $\alpha$ IRS- 1 or $\alpha$ IRS- 2 antibodies and decreases of $35 \%$ and $20 \%$, respectively, were detected in the hypothalamus of obese rats when compared to the lean controls. Based on differential affinity of IRS-1 and IRS-2 antibodies and on data described above we conclude that the relative abundance of IRS-1 is considerably lower than that of IRS-2 in hypothalamus of lean rats. It is noteworthy that the differences between IRS-1 and IRS-2 are preserved in obese rats (Fig. 3c). The protein levels of PI3-kinase were not different in the hypothalamus of lean and obese animals. The basal levels of IRS-1 and IRS-2 serine phosphorylation were compared in IRS- 1 and IRS-2 immunoprecipitates from the hypothalamus of both lean and obese rats. The basal levels of IRS-1 and IRS-2 serine phosphorylation were 4.4 and 3.2 times higher in obese rats than in the lean ones (Fig. 3d).

Distribution of IR, IRS-1 and IRS-2 in hypothalamus of obese and lean Zucker rats. In the face of an apparent molecular impairment in insulin signal transduction in the hypothalamus of obese Zucker rats, we decided to test if there would be any difference in the expression and histological distribution of IR, IRS-1 and IRS-2 between hypothalami of obese and lean Zucker rats. In an initial series of experiments, hypothalami of three obese and three lean Zucker rats were paraformaldehyde fixed and utilized in peroxidase staining with IR, IRS-1 and IRS-2 primary antibodies. Most IR immunoreactivity was detected in arcuate nucleus (Arc), with only scattered neurons containing IR appearing in periventricular nucleus (PVN) and posterior hypothalamus (PH) (Fig. 4a). The same pattern of distribution was true for IRS-2. However, IRS-1 hypothalamic distribution had a particular characteristic, with positive IRS-1 staining in several neurons of $\mathrm{PH}$ and only some few cells staining positive for IRS- 1 in Arc (Fig. 4a, inset Arc/IRS-1 intersection). There were no differences in distribution of IR, IRS-1 and IRS-2 between hypothalami of obese and lean rats. In order to investigate co-expression of IR with both IRS-1 and IRS-2 we carried out double-staining confocal microscopy (Fig. 4b). By this technique most neurons expressing IR in Arc were shown to possess IRS-2, while only some of them co-expressed IRS-1. Moreover, in PVN some, but not all cells expressing IR were also positive for IRS-2. No neurons co-expressing IR and IRS-1 were seen in PVN. Finally, at

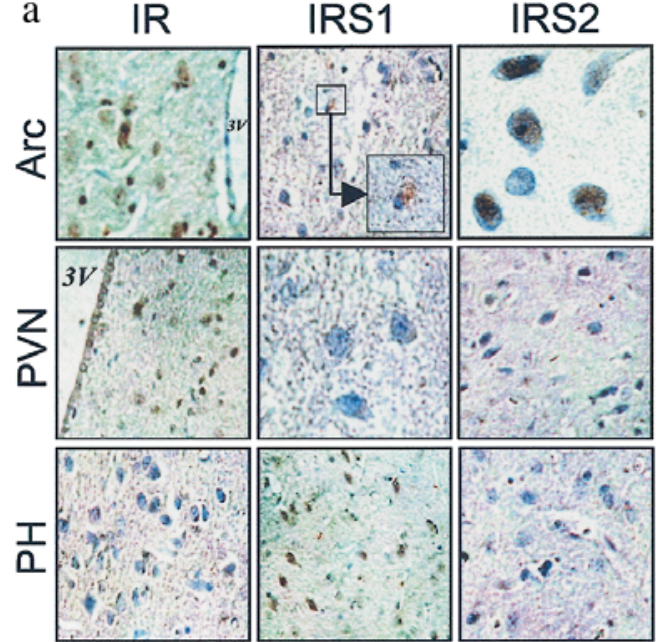

b
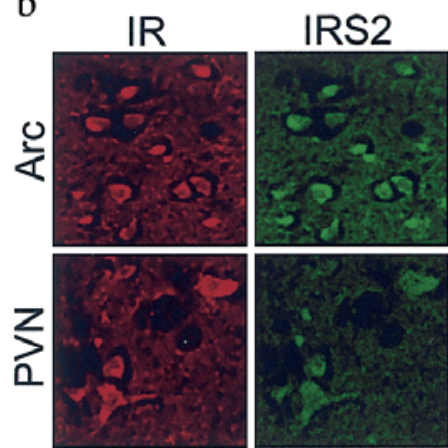

Merge
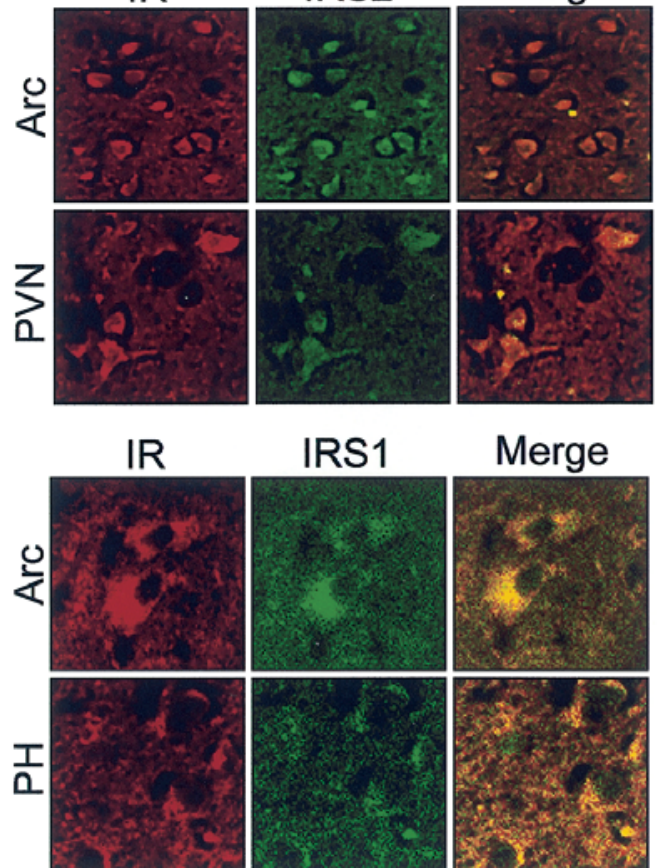

Merge

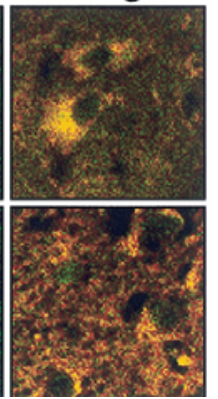

Fig. 4a, b. Immunohistochemical evaluation of IR, IRS1 and IRS2 distribution in hypothalamus of Zucker ( $f a / f a)$ rats. In paraformaldehyde fixed rat $(f a / f a)$ hypothalamic sections $(5 \mu \mathrm{m})$ stained with the peroxidase technique (a) anti-IR (first vertical column); anti-IRS1 (second vertical column); antiIRS2 (third vertical column). (b) Laser confocal analysis of hypothalamic sections of obese Zucker rats double-labelled with anti-IR (red staining) and anti-IRS-1 or anti-IRS-2 (green staining) antibodies. Arc, arcuate nucleus; PVN, perive nucleus; $\mathrm{PH}$, posterior hypothalamic area; $3 \mathrm{~V}$, third ventricle

$\mathrm{PH}$, a site of high expression of IRS-1, we could detect neurons expressing only IRS-1 and no IR and some few cells expressing both proteins (Fig. 4b, PH merge that a neuron containing only IRS-1 stains clearly in green). 
a

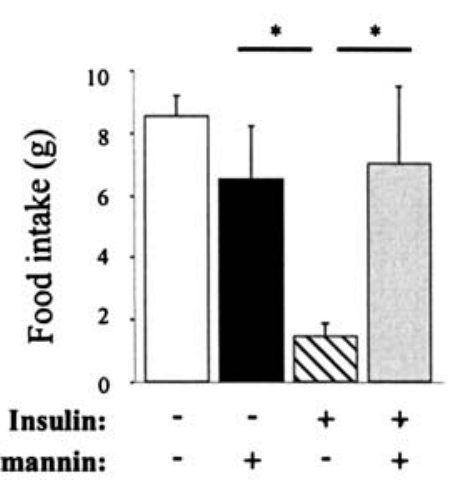

$\mathrm{c}$

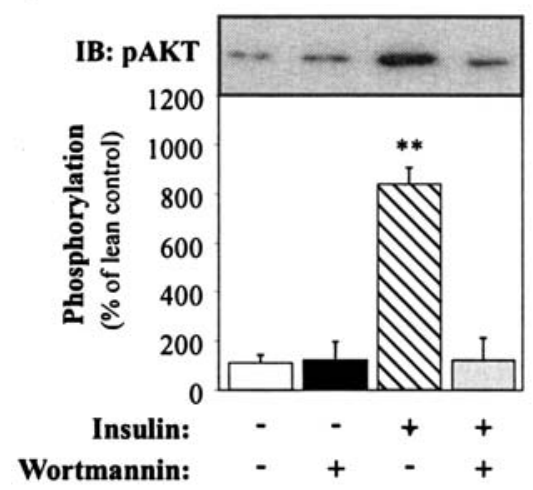

Fig. 5a-d. Blockade of insulin-induced inhibition of food intake by PI 3-kinase inhibitors. (a, b) Lean rats fasted for $6 \mathrm{~h}$ were injected i.c.v. with either vehicle $(2 \mu \mathrm{l})$, Wortmannin $(100 \mathrm{nmol} / \mathrm{l})$ or LY294002 $(50 \mu \mathrm{mol} / \mathrm{l})$ and 30 min later were injected with vehicle $(2 \mu \mathrm{l})$ or insulin $(200 \mathrm{mU})$ and were immediately exposed to food for $12 \mathrm{~h}$. Data are expressed as means \pm SEM of $6-8$ animals per group. ${ }^{*} p<0.05$ relative to controls (c, d) Insulin-stimulated serine phosphorylation of Akt in hypothalamus of lean Zucker rats in vivo. Pre-treatment with either vehicle $(2 \mu \mathrm{l})$, Wortmannin $(100 \mathrm{nmol} / \mathrm{l})$ or LY294002 $(50 \mu \mathrm{mol} / \mathrm{l})$ was followed $30 \mathrm{~min}$ later by i.c.v. administration of vehicle $(2 \mu \mathrm{l})$ or insulin $(200 \mathrm{mU})$ for $15 \mathrm{~min}$, then the hypothalamus was lysed and the proteins were separated by SDS-PAGE on $12 \%$ gels and blotted with phosphoserine-specific AKT antibodies (IB, immunoblotting). A representative western blot of each group is shown. Data (means \pm SEM; $n=8)$ are expressed as relative to control. ${ }^{*} p<0.05$, relative to controls

Role of PI 3-kinase in anorectic response to insulin. Pharmacological inhibitors of PI3-kinase activity, such as Wortmannin, can block insulin activity in vitro, suggesting that PI3-kinase-dependent signalling is needed for certain intracellular responses to insulin. We tested whether the inhibitory effects of insulin on food intake depend on PI3-kinase by i.c.v. infusion of PI 3-kinase inhibitors into lean rats. Treatment with insulin reduced 12-h food intake in rats pre-treated with vehicle, but we did not detect insulin-induced anorexia after pre-treatment with Wortmannin (Fig. 5a). b

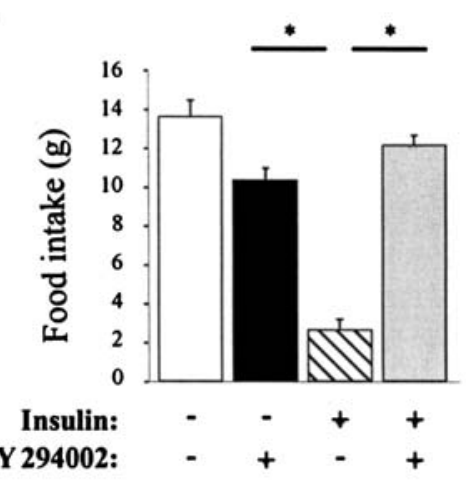

d

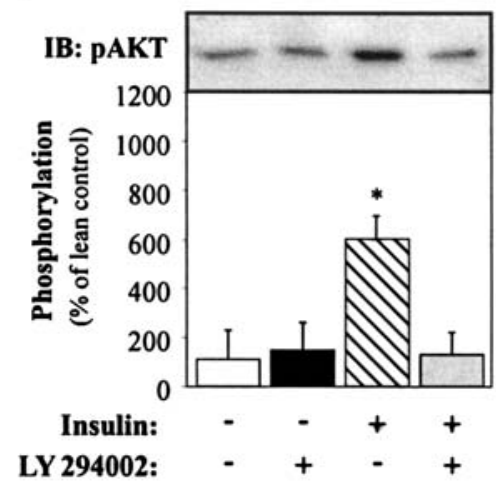

By using LY294002, instead of Wortmannin in a different group of rats, we confirmed that infusion of PI3-kinase inhibitors into the lateral cerebral ventricle prevents the reduction in food intake induced by i.c.v. administration of insulin (Fig. 5b). Akt is a serine/ threonine kinase that is serine-phosphorylated and can be activated by insulin through the PI3-kinase pathway. In the hypothalamus from lean rats, insulin induced a marked increase in serine phosphorylation of Akt (Fig. 4b,c-lane 3). To confirm the biological efficacy of PI3-kinase blockage with Wortmannin and LY294002 we determined the effect of insulin on the activation of Akt in rats pretreated with Wortmannin and LY294002. Wortmannin and LY294002 prevented insulin-induced serine phosphorylation of Akt in the hypothalamus of lean rats (Fig. 5c,d-lane 4).

Serine phosphorylation of Akt and tyrosine phosphorylation of MAP kinase (ERK-1/2) in hypothalamic tissue. In hypothalamus from lean rats, insulin (2 and $200 \mathrm{mU}$ ) increased serine phosphorylation of Akt by 5.8- and 8.7-fold, respectively. The basal levels of serine phosphorylation of Akt were higher in hypothalamus of obese rats compared to lean animals $(p<0.05$; $n=10$ ), and insulin ( 2 and $200 \mathrm{mU}$ ) increased Akt serine phosphorylation by only 1.5 - and 1.9 -fold respectively, in those animals. Compared to the lean rats there were reductions of $51 \%$ and $55 \%$ in insulin-induced Akt phosphorylation in hypothalamus of obese rats (Fig. 6a). The protein levels of Akt were not dif- 


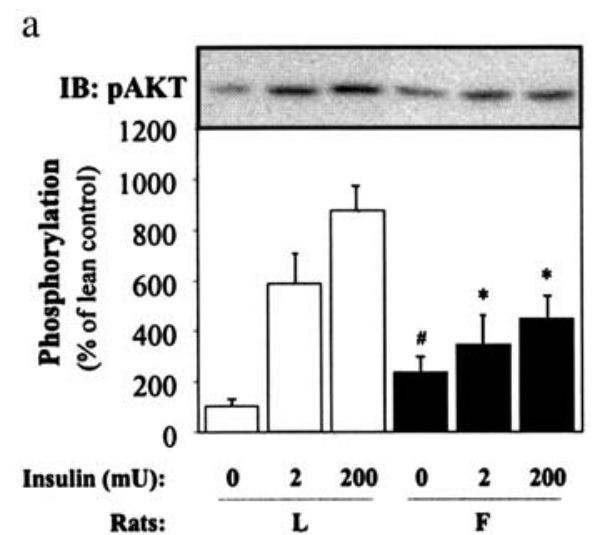

Fig. 6a, b. Effects of insulin on serine phosphorylation of Akt and tyrosine phosphorylation of MAP kinase (ERK-1/2) in hypothalamus of lean (L) and obese (F) Zucker rats in vivo. $(\mathbf{a}, \mathbf{b})$ Insulin-stimulated serine phosphorylation of Akt in hypothalamus of lean $(\mathrm{L})$ and obese $(\mathrm{F})$ Zucker rats in vivo. Rats fasted for $6 \mathrm{~h}$ were injected i.c.v. with vehicle $(2 \mu \mathrm{l})$ or insulin (200 $\mathrm{mU})$, the hypothalamus was then lysed and the proteins were separated by SDS-PAGE on $12 \%$ gels and blotted with phosphoserine-specific AKT antibodies and with phosphotyrosine-specific ERK antibodies (IB, immunoblotting). A representative western blot of each group is shown. Data (means $\pm \mathrm{SEM} ; n=10)$ are expressed as relative to control, assigning a value of $100 \%$ to the lean insulin mean. ${ }^{\#} p<0.05$, vehicle lean vs. vehicle obese, $* p<0.05$, insulin lean vs. insulin obese. (a, b-bottom panel) Stripped membranes were reblotted with anti Akt and anti-ERK antibodies

ferent in the hypothalamus of lean and obese animals (Fig. 6a bottom).

Using antibodies against tyrosine-phosphorylated ERK-1/2, the levels of ERK-1/2 phosphorylation were examined in hypothalamus after insulin stimulation. Insulin stimulated tyrosine phosphorylation of ERK$1 / 2$ equally in the hypothalamus of lean and obese rats. Insulin (2 and $200 \mathrm{mU}$ ) increased tyrosine phosphorylation of ERK-1/2 by 3.7- and 4.4-fold in the hypothalamus of lean rats, respectively, and by 3.5 - and 4.2-fold in the hypothalamus of obese rats (Fig. 6b). The protein levels of Shc (data not shown) and ERK$1 / 2$ (Fig. 6b bottom) were not different in the hypothalamus of lean and obese animals.

\section{Discussion}

In this study, we have characterized insulin signalling in the hypothalamus of lean and obese Zucker rats. Obese Zucker rats have insulin resistance, hyperinsulinaemia, hyperlipidaemia and glucose intolerance, features similar to those presented in obesity-related insulin resistance and Type 2 diabetes mellitus [34]. We show that treatment with insulin reduces food in-

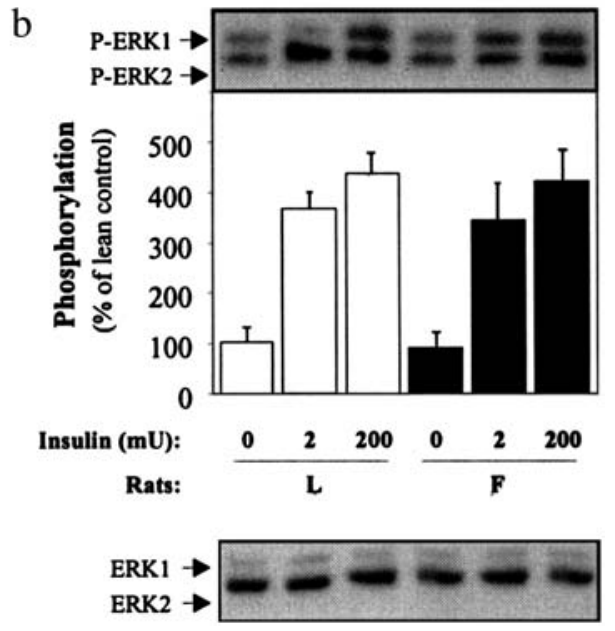

take in lean rats pre-treated with vehicle, but we did not detect insulin-induced anorexia after pre-treatment with PI3-kinase inhibitors. In contrast, in accordance with a previous report [24], our results show that central insulin administration is less effective in reducing food intake in the obese Zucker rats. In addition, our data show an impairment of insulin activation of the PI3-kinase-Akt pathway in these animals. However, insulin-stimulated tyrosine phosphorylation of ERK$1 / 2$ MAP kinase is similar in both phenotypes. Defective and pathway selective insulin action in the brain could thus contribute to the pathogenesis of obesity in the $f a / f a$ rats.

Several mechanisms might be enrolled in the pathogenesis of insulin resistance in hypothalamus of obese Zucker rats. By decreasing the ability of circulating insulin to enter brain interstitial fluid, where it can bind to neuronal insulin receptors, impaired insulin transport across endothelial cells of the bloodbrain barrier is one potential mechanism. Several studies have indicated that insulin uptake into the brain is facilitated by insulin receptors expressed by endothelial cells in the blood-brain barrier that function as insulin transporters $[35,36]$. The relationship between cerebrospinal fluid and plasma insulin concentrations is not linear but is saturable, consistent with a receptor-mediated transport process. This non-linear relationship has been observed in moderate diet-induced obesity rats [37]. High-fat diet-induced obesity is also associated with reduced brain insulin transport in dogs [38], and genetically obese Zucker rats have impaired brain insulin transport [39], which can be ascribed to a decreased number of brain capillary insulin receptors [35]. Here we show that the sites of insulin-signalling impairment seem to be at the IR and post-receptor levels in the hypothalamus of obese Zucker rats. Insulin-induced IR tyrosine phosphorylation is lower in the hypothalamus of obese compared to the lean rats. The reduction in IR tyrosine phosphorylation in the hypothalamus is similar to that observed in the liver and vascular cells of obese Zucker rats [40]. 
Severe insulin resistance is a well-known feature of leptin receptor mutation in the Zucker rats [34]. Insulin resistance and hyperinsulinaemia occur early during the life of these animals, are out of proportion to their adiposity at early stages, and exceed the insulin resistance and hyperinsulinaemia promoted by hyperphagia and obesity. Leptin's effect on insulin sensitivity involves the central actions of leptin to modify metabolism, and its direct effects at the level of insulin target tissues [22]. Substantial data support the notion that leptin could have important effects through direct actions on peripheral target cells, including beta cells, liver, muscle, and fat. Some evidence suggests that in tissues such as muscle and beta cells, leptin promotes lipid oxidation and inhibits lipid synthesis, which would improve insulin sensitivity [41, 42, 43]. In contrast to the reduced insulin effects in hypothalamus of obese rats, insulin-induced reduction in food intake is similar in lean $+/+$ and lean $+/ f a$ rats. These results could suggest that intermediate amount of functional leptin receptor might be sufficient to the positive cross-talk between insulin and leptin. However, in the absence of leptin's action in obese Zucker rats, the insulin signal transduction is compromised in hypothalamus despite the very high fasting and post-prandial insulin concentrations observed in these animals. Another possibility not to be excluded is that the hypothalamic insulin resistance in obese Zucker rats could be a secondary effect of obesity. Thus, the investigation of insulin signalling in hypothalamus of animal models of diet-induced obesity is important and deserves further exploration.

As observed in the liver [44], a moderate decrease in IRS-1 and IRS-2 protein expression occurs in the hypothalamus of the obese rats. In parallel, there is also a decrease in IRS-1 and IRS-2 tyrosine phosphorylation, reflecting the decrease in protein levels as well as a decrease in the stoichiometry of phosphorylation. These reductions are accompanied by a decrease in insulin-induced IRS- 1 and IRS-2 association with PI3-kinase and Akt phosphorylation. However, the basal level of Akt serine phosphorylation is higher in the hypothalamus of obese animals, probably as a consequence of the hyperinsulinaemia, but only a mild increase occurs after acute insulin infusion.

There are probably a number of mechanisms that lead to an impairment of the insulin-signalling pathway in the hypothalamus of obese Zucker rats. Our results show that increased serine phosphorylation of IR, IRS-1 and IRS-2 could be one of these mechanisms. Previous studies clearly showed that an increase in IR and IRSs serine phosphorylation could induce insulin resistance, pointing to this as an important mechanism in the control of insulin signalling $[45,46,47]$. It has been reported that activation of PKC induces serine phosphorylation of IR, which can inhibit its tyrosine kinase activity, leading to a decrease in insulin-induced PI3-kinase activity [48, 49].
Activation of protein kinase $\mathrm{C}-\alpha,-\beta,-\varepsilon$, and $-\delta$ has been reported in skeletal muscle of obese Zucker and diabetic Goto-Kakizaki rats [50]. Tumor-necrosis factor- $\alpha$ (TNF- $\alpha$ ) has been suggested as an important mediator of insulin resistance in obese animals through its overexpression from fat tissue [51]. TNF$\alpha$ has been shown to produce serine phosphorylation of IRS-1, resulting in reduced insulin receptor kinase activity and insulin resistance [46]. In rodents, antiTNF- $\alpha$ reagents improved insulin resistance [52]. The reduction in IRS-1 and IRS-2 protein levels in hypothalamus of obese rats could also contribute to hypothalamic insulin resistance in these animals. These reductions in IRSs protein expression might be secondary to increased degradation of these proteins, as a consequence of increased serine phosphorylation levels [53], and/or be under transcriptional control. In this regard, it was recently postulated that the genes encoding IRSs are under transcriptional control of leptin-induced JAK-STAT signalling pathways, reinforcing the positive cross-talk between insulin and leptin [54]. According to immunohistochemical studies, differences in sub-anatomical expression of IRS1 and IRS-2 within the hypothalamus do not occur between lean and obese Zucker rats; indeed, the relative abundance of IRS-1 is considerably lower than that of IRS-2 in both lean and obese animals. Altogether, this data with the results of confocal microscopy showing that there is a more concordant presence of IR and IRS-2 but not IRS-1 in neurons of different areas of hypothalamus, makes it reasonable to speculate that IRS-2 could have a more important role than IRS-1 in the insulin-induced activation of the PI 3-kinase-Akt pathway in rat hypothalamus. These results are in accordance with the recent report of increased food intake and fat storage in female IRS-2 knockout mice [55], a feature not observed in IRS-1 knockout mice [56].

Selective impairment of insulin signalling through PI3-kinase pathway in the hypothalamus could be pathophysiologically important in the development of obesity. Recent studies have shown that activation of the PI3-kinase pathway could be involved in the anorexigenic effect of insulin or leptin [27, 28]. Taken together with our data in an insulin-resistant state, these findings might indicate that the anti-obesity actions induced by insulin could be blunted due to the partial inhibition of the PI3-kinase pathway suggesting that neuronal PI3-kinase is important for the effects of insulin on food intake. If the mechanism used by insulin to reduce food intake is PI3-kinase-dependent, as our results suggest, the defective activation of PI 3-kinase in hypothalamic neurons could attenuate the ability of insulin to reduce food intake in the obese Zucker rats.

In previous studies in rat tissues, IRS- 1 tyrosine phosphorylation correlated to a greater extent to insulin receptor phosphorylation levels, than to IRS-1 pro- 
tein expression, suggesting that modest reductions in IRS-1 protein amount would not be sufficient to affect insulin signal transduction [57]. In light of these previous data we can suggest that the increase in serine phosphorylation level of IR and IRS-1 could be the main determinant of reductions in tyrosine phosphorylation of these proteins.

The profound insulin resistance on the PI3-kinase pathway contrasts with the ability of insulin to stimulate the MAP kinase pathway in the hypothalamus of the obese rats. Insulin resistance does not affect the MAP kinase pathway, since insulin administration increased ERK1/2 phosphorylation to the same extent in both lean and obese rats. This finding of selective insulin resistance has been recently observed in the vasculature of Zucker rats [40]. Two possible reasons for this difference can be proposed: alternate insulin signalling pathways and differential signal amplification. With regard to the former, the MAP kinase pathway can be activated through Grb2/Sos interaction with IRS-1/2 or Shc. As IRS-1 tyrosine phosphorylation is dramatically reduced in the obese animals, it is possible that insulin activation of the MAP kinase pathway in vivo primarily occurs through Shc activation. Evidence from in vitro and in vivo studies support this concept $[58,59]$. Maintenance of normal insulin stimulation of the MAP kinase pathway in the presence of insulin resistance on the PI3-kinase pathway might be important in the development of insulin resistance. ERKs can phosphorylate IRS-1 on serine residues [60], and serine phosphorylation of IRS-1 and of the insulin receptor itself, as described above, can be implicated in desensitizing insulin receptor signalling [61].

In summary, our data provide evidence that insulin can activate both the PI3-kinase-Akt and MAP kinase pathways in the hypothalamus and that the ability of insulin to reduce food intake is PI3-kinase-dependent. In obese Zucker rats, PI3-kinase pathway seems to be selectively blunted in hypothalamic tissues, compared with MAP kinase. These findings support the hypothesis that insulin could have anti-obesity actions mediated by the PI3-kinase pathway and that the impaired PI3-kinase signalling pathway in the hypothalamus might lead to the development of obesity and insulin resistance in the obese Zucker rats.

Acknowledgements. This study was supported by grants from the Fundação de Amparo à Pesquisa do Estado de São Paulo (FAPESP) and Conselho Nacional de Desenvolvimento Científico e Tecnológico $(\mathrm{CNPq})$, Brazil. We are grateful to Luís Janeri for technical assistance.

\section{References}

1. Havrankova J, Roth J, Brownstein M (1978) Insulin receptors are widely distributed in the central nervous system of the rat. Nature 272:827-829
2. Werther GA, Hogg A, Oldfield BJ, McKinley MJ, Figdor R, Allen AM, Mendelsohn FA (1987) Localization and characterization of insulin receptors in rat brain and pituitary gland using in vitro autoradiography and computerized densitometry. Endocrinology 121:1562-1570

3. Marks JL, Porte D Jr, Stahl WL, Baskin DG (1990) Localization of insulin receptor mRNA in rat brain by in situ hybridization. Endocrinology 127:3234-3236

4. Obici S, Feng Z, Karkanias G, Baskin DG, Rossetti L (2002) Decreasing hypothalamic insulin receptors causes hyperphagia and insulin resistance in rats. Nat Neurosci 5:566-572

5. Baskin DG, Figlewicz Lattemann D, Seeley RJ, Woods SC, Porte D Jr, Schwartz MW (1999) Insulin and leptin: dual adiposity signals to the brain for the regulation of food intake and body weight. Brain Res 848:114-123

6. Schwartz MW, Sipols AJ, Marks JL, Sanacora G, White JD, Scheurink A, Kahn SE, Baskin DG, Woods SC, Figlewicz DP et al. (1992) Inhibition of hypothalamic neuropeptide Y gene expression by insulin. Endocrinology 130:3608-3616

7. Torsoni MA, Carvalheira JB, Pereira-Da-Silva M, de Carvalho-Filho MA, Saad MJ, Velloso LA (2003) Molecular and functional resistance to insulin in hypothalamus of rats exposed to cold. Am J Physiol Endocrinol Metab 285: E216-E223

8. Carvalheira JB, Siloto RM, Ignacchitti I, Brenelli SL, Carvalho CR, Leite A, Velloso LA, Gontijo JA, Saad MJ (2001) Insulin modulates leptin-induced STAT3 activation in rat hypothalamus. FEBS Lett 500:119-124

9. Sun XJ, Rothenberg P, Kahn CR, Backer JM, Araki E, Wilden PA, Cahill DA, Goldstein BJ, White MF (1991) Structure of the insulin receptor substrate IRS-1 defines a unique signal transduction protein. Nature 352:73-77

10. Sun XJ, Wang LM, Zhang Y, Yenush L, Myers MG Jr, Glasheen E, Lane WS, Pierce JH, White MF (1995) Role of IRS-2 in insulin and cytokine signalling. Nature 377:173-177

11. Lavan BE, Lane WS, Lienhard GE (1997) The 60-kDa phosphotyrosine protein in insulin-treated adipocytes is a new member of the insulin receptor substrate family. J Biol Chem 272:11439-11443

12. Kovacina KS, Roth RA (1993) Identification of SHC as a substrate of the insulin receptor kinase distinct from the GAP-associated $62 \mathrm{kDa}$ tyrosine phosphoprotein. Biochem Biophys Res Commun 192:1303-1311

13. Folli F, Saad MJ, Backer JM, Kahn CR (1992) Insulin stimulation of phosphatidylinositol 3-kinase activity and association with insulin receptor substrate 1 in liver and muscle of the intact rat. J Biol Chem 267:22171-22177

14. Saad MJ, Folli F, Kahn JA, Kahn CR (1993) Modulation of insulin receptor, insulin receptor substrate-1, and phosphatidylinositol 3-kinase in liver and muscle of dexamethasone-treated rats. J Clin Invest 92:2065-2072

15. Kuhne MR, Pawson T, Lienhard GE, Feng GS (1993) The insulin receptor substrate 1 associates with the SH2-containing phosphotyrosine phosphatase Syp. J Biol Chem 268:11479-11481

16. Yamauchi K, Milarski KL, Saltiel AR, Pessin JE (1995) Protein-tyrosine-phosphatase SHPTP2 is a required positive effector for insulin downstream signaling. Proc Natl Acad Sci USA 92:664-668

17. Skolnik EY, Lee CH, Batzer A, Vicentini LM, Zhou M, Daly R, Myers MJ Jr, Backer JM, Ullrich A, White MF et al. (1993) The SH2/SH3 domain-containing protein GRB2 interacts with tyrosine-phosphorylated IRS1 and Shc: implications for insulin control of ras signalling. EMBO J 12:1929-1936 
18. Brozinick JT Jr, Birnbaum MJ (1998) Insulin, but not contraction, activates Akt/PKB in isolated rat skeletal muscle. J Biol Chem 273:14679-14682

19. Sale EM, Atkinson PG, Sale GJ (1995) Requirement of MAP kinase for differentiation of fibroblasts to adipocytes, for insulin activation of p90 S6 kinase and for insulin or serum stimulation of DNA synthesis. EMBO J 14:674-684

20. Jhun BH, Haruta T, Meinkoth JL, Leitner W, Draznin B, Saltiel AR, Pang L, Sasaoka T, Olefsky JM (1995) Signal transduction pathways leading to insulin-induced early gene induction. Biochemistry 34:7996-8004

21. Kim SJ, Kahn CR (1997) Insulin regulation of mitogen-activated protein kinase kinase (MEK), mitogen-activated protein kinase and casein kinase in the cell nucleus: a possible role in the regulation of gene expression. Biochem $\mathrm{J}$ 323:621-627

22. Kahn BB, Flier JS (2000) Obesity and insulin resistance. J Clin Invest 106:473-481

23. Figlewicz DP, Dorsa DM, Stein LJ, Baskin DG, Paquette T, Greenwood MR, Woods SC, Porte D Jr (1985) Brain and liver insulin binding is decreased in Zucker rats carrying the 'fa' gene. Endocrinology 117:1537-1543

24. Ikeda H, West DB, Pustek JJ, Figlewicz DP, Greenwood MR, Porte D Jr, Woods SC (1986) Intraventricular insulin reduces food intake and body weight of lean but not obese Zucker rats. Appetite 7:381-386

25. Schwartz MW, Marks JL, Sipols AJ, Baskin DG, Woods SC, Kahn SE, Porte D Jr (1991) Central insulin administration reduces neuropeptide Y mRNA expression in the arcuate nucleus of food-deprived lean $(\mathrm{Fa} / \mathrm{Fa})$ but not obese (fa/fa) Zucker rats. Endocrinology 128:2645-2647

26. Bruning JC, Gautam D, Burks DJ, Gillette J, Schubert M, Orban PC, Klein R, Krone W, Muller-Wieland D, Kahn CR (2000) Role of brain insulin receptor in control of body weight and reproduction. Science 289:2122-2125

27. Niswender KD, Morton GJ, Stearns WH, Rhodes CJ, Myers MG Jr, Schwartz MW (2001) Intracellular signalling. Key enzyme in leptin-induced anorexia. Nature 413: 794-795

28. Niswender KD, Morrison CD, Clegg DJ, Olson R, Baskin DG, Myers MG Jr, Seeley RJ, Schwartz MW (2003) Insulin activation of phosphatidylinositol 3-kinase in the hypothalamic arcuate nucleus: a key mediator of insulin-induced anorexia. Diabetes 52:227-231

29. Scott AM, Atwater I, Rojas E (1981) A method for the simultaneous measurement of insulin release and B cell membrane potential in single mouse islets of Langerhans. Diabetologia 21:470-475

30. Paxinos G, Watson C (1998) The rat brain in stereotaxic coordinates 4th edn. Academic Press, San Diego

31. Manil L, Motte P, Pernas P, Troalen F, Bohuon C, Bellet D (1986) Evaluation of protocols for purification of mouse monoclonal antibodies. Yield and purity in two-dimensional gel electrophoresis. J Immunol Methods 90:25-37

32. Fuglistaller P (1989) Comparison of immunoglobulin binding capacities and ligand leakage using eight different protein A affinity chromatography matrices. J Immunol Methods 124:171-177

33. Araujo EP, Amaral ME, Souza CT, Bordin S, Ferreira F, Saad MJ, Boschero AC, Magalhaes EC, Velloso LA (2002) Blockade of IRS1 in isolated rat pancreatic islets improves glucose-induced insulin secretion. FEBS Lett 531:437-442

34. Bray GA (1977) The Zucker-fatty rat: a review. Fed Proc 36:148-153

35. Schwartz MW, Figlewicz DF, Kahn SE, Baskin DG, Greenwood MR, Porte D Jr (1990) Insulin binding to brain capillaries is reduced in genetically obese, hyperinsulinemic Zucker rats. Peptides 11:467-472

36. Baura GD, Foster DM, Porte D Jr, Kahn SE, Bergman RN, Cobelli C, Schwartz MW (1993) Saturable transport of insulin from plasma into the central nervous system of dogs in vivo. A mechanism for regulated insulin delivery to the brain. J Clin Invest 92:1824-1830

37. Israel PA, Park CR, Schwartz MW, Green PK, Sipols AJ, Woods SC, Porte D Jr, Figlewicz DP (1993) Effect of dietinduced obesity and experimental hyperinsulinemia on insulin uptake into CSF of the rat. Brain Res Bull 30:571-575

38. Kaiyala KJ, Prigeon RL, Kahn SE, Woods SC, Schwartz MW (2000) Obesity induced by a high-fat diet is associated with reduced brain insulin transport in dogs. Diabetes 49:1525-1533

39. Stein LJ, Dorsa DM, Baskin DG, Figlewicz DP, Porte D Jr, Woods SC (1987) Reduced effect of experimental peripheral hyperinsulinemia to elevate cerebrospinal fluid insulin concentrations of obese Zucker rats. Endocrinology 121: $1611-1615$

40. Jiang ZY, Lin YW, Clemont A, Feener EP, Hein KD, Igarashi M, Yamauchi T, White MF, King GL (1999) Characterization of selective resistance to insulin signaling in the vasculature of obese Zucker (fa/fa) rats. J Clin Invest 104:447-457

41. Kamohara S, Burcelin R, Halaas JL, Friedman JM, Charron MJ (1997) Acute stimulation of glucose metabolism in mice by leptin treatment. Nature 389:374-377

42. Kim YB, Uotani S, Pierroz DD, Flier JS, Kahn BB (2000) In vivo administration of leptin activates signal transduction directly in insulin-sensitive tissues: overlapping but distinct pathways from insulin. Endocrinology 141:23282339

43. Carvalheira JB, Ribeiro EB, Folli F, Velloso LA, Saad MJ (2003) interaction between leptin and insulin signaling pathways differentially affects the JAK-STAT and PI 3-kinase-mediated signaling in rat liver. Biol Chem 384:151159

44. Anai M, Funaki M, Ogihara T, Terasaki J, Inukai K, Katagiri H, Fukushima Y, Yazaki Y, Kikuchi M, Oka Y, Asano T (1998) Altered expression levels and impaired steps in the pathway to phosphatidylinositol 3-kinase activation via insulin receptor substrates 1 and 2 in Zucker fatty rats. Diabetes 47:13-23

45. Tanti JF, Gremeaux T, van Obberghen E, Le MarchandBrustel Y (1994) Serine/threonine phosphorylation of insulin receptor substrate 1 modulates insulin receptor signaling. J Biol Chem 269:6051-6057

46. Hotamisligil GS, Peraldi P, Budavari A, Ellis R, White MF, Spiegelman BM (1996) IRS-1-mediated inhibition of insulin receptor tyrosine kinase activity in TNF-alpha- and obesity-induced insulin resistance. Science 271:665-668

47. Mothe I, Van Obberghen E (1996) Phosphorylation of insulin receptor substrate- 1 on multiple serine residues, 612, 632, 662, and 731, modulates insulin action. J Biol Chem 271:11222-11227

48. Chin JE, Dickens M, Tavare JM, Roth RA (1993) Overexpression of protein kinase $\mathrm{C}$ isoenzymes alpha, beta I, gamma, and epsilon in cells overexpressing the insulin receptor. Effects on receptor phosphorylation and signaling. J Biol Chem 268:6338-6347

49. Pillay TS, Xiao S, Olefsky JM (1996) Glucose-induced phosphorylation of the insulin receptor. Functional effects and characterization of phosphorylation sites. J Clin Invest 97:613-620

50. Avignon A, Yamada K, Zhou X, Spencer B, Cardona O, Saba-Siddique S, Galloway L, Standaert ML, Farese RV 
(1996) Chronic activation of protein kinase C in soleus muscles and other tissues of insulin-resistant type II diabetic Goto-Kakizaki (GK), obese/aged, and obese/Zucker rats. A mechanism for inhibiting glycogen synthesis. Diabetes 45:1396-1404

51. Hotamisligil GS, Budavari A, Murray D, Spiegelman BM (1994) Reduced tyrosine kinase activity of the insulin receptor in obesity- diabetes. Central role of tumor necrosis factor-alpha. J Clin Invest 94:1543-1549

52. Ventre J, Doebber T, Wu M, MacNaul K, Stevens K, Pasparakis M, Kollias G, Moller DE (1997) Targeted disruption of the tumor necrosis factor-alpha gene: metabolic consequences in obese and non-obese mice. Diabetes 46:1526-1531

53. Greene MW, Sakaue H, Wang L, Alessi DR, Roth RA (2003) Modulation of insulin-stimulated degradation of human insulin receptor substrate- 1 by Serine 312 phosphorylation. J Biol Chem 278:8199-8211

54. Niswender KD, Schwartz MW (2003) Insulin and leptin revisited: adiposity signals with overlapping physiological and intracellular signaling capabilities. Front Neuroendocrinol 24:1-10

55. Burks DJ, Mora JF de, Schubert M, Withers DJ, Myers MG, Towery HH, Altamuro SL, Flint CL, White MF (2000) IRS-2 pathways integrate female reproduction and energy homeostasis. Nature 407:377-382
56. Araki E, Lipes MA, Patti ME, Bruning JC, Haag B, Johnson RS, Kahn CR (1994) Alternative pathway of insulin signalling in mice with targeted disruption of the IRS-1 gene. Nature 372:186-190

57. Saad MJ, Araki E, Miralpeix M, Rothenberg PL, White MF, Kahn CR (1992) Regulation of insulin receptor substrate- 1 in liver and muscle of animal models of insulin resistance. J Clin Invest 90:1839-1849

58. Sasaoka T, Draznin B, Leitner JW, Langlois WJ, Olefsky JM (1994) Shc is the predominant signaling molecule coupling insulin receptors to activation of guanine nucleotide releasing factor and p21ras-GTP formation. J Biol Chem 269:10734-10738

59. Paez-Espinosa EV, Rocha EM, Velloso LA, Boschero AC, Saad MJ (1999) Insulin-induced tyrosine phosphorylation of Shc in liver, muscle and adipose tissue of insulin resistant rats. Mol Cell Endocrinol 156:121-129

60. De Fea K, Roth RA (1997) Modulation of insulin receptor substrate- 1 tyrosine phosphorylation and function by mitogen-activated protein kinase. J Biol Chem 272:3140031406

61. Dunaif A, Xia J, Book CB, Schenker E, Tang Z (1995) Excessive insulin receptor serine phosphorylation in cultured fibroblasts and in skeletal muscle. A potential mechanism for insulin resistance in the polycystic ovary syndrome. J Clin Invest 96:801-810 